\title{
Case study of the relationship between heat-resistant paint and comfortable indoor temperatures
}

\author{
Takashi Oda $^{1,2,{ }^{*}, \text { Kimihiro Yamanaka }}{ }^{1}$, Mitsuyuki Kawakami ${ }^{3}$ \\ ${ }^{1}$ System Design of Tokyo Metropolitan University, Tokyo, Japan \\ ${ }^{2}$ Nissin Sangyo Co., Ltd., Tokyo, Japan \\ ${ }^{3}$ Human Sciences of Kanagawa University, Kanagawa, Japan
}

\section{Email address:}

oda-takashi1@ed.tmu.ac.jp (T. Oda), kiyamana@tmu.ac.jp (K. Yamanaka), kawakamim@kanagawa-u.ac.jp (M. Kawakami)

\section{To cite this article:}

Takashi Oda, Kimihiro Yamanaka, Mitsuyuki Kawakami. Case Study of The Relationship between Heat-Resistant Paint and Comfortable Indoor Temperatures. International Journal of Environmental Protection and Policy. Vol. 2, No. 5, 2014, pp. 185-189.

doi: $10.11648 /$ j.ijepp.20140205.17

\begin{abstract}
Higher temperatures can cause health problems such as heat stroke, and the number of cases increases sharply in people over 65 years old. Elderly people have a high risk of heat stroke, not only during the day but also at night, and they also have a reduced sensitivity to heat, so the possibility that countermeasures are taken too late increases. In such cases adverse effects cannot be prevented by measures involving voluntary action, including the provision of air conditioning. For these reasons, heat stroke countermeasures involving methods that do not depend on the sensory functions of the target person are needed. Therefore, we propose a new method for controlling indoor temperatures using heat-resistant paint. In this study, two verification experiments were conducted totest the proposed temperature control method in cargo containers and communal buildings. The effectiveness of the methods was apparent in measurements of temperature and electricity consumption.
\end{abstract}

Keywords: Heat-Resistant Paint, Temperature Control, Energy Saving

\section{Introduction}

The aging of Japanese society has been progressing over the past several years, and people aged over 65 years now constitute more than $20 \%$ of the population. This change has also occurred in many other developed countries [1-3]. For this reason, the work force at production sites is becoming dependent on elderly workers, and the aging of workers is becoming a major social problem. Furthermore, it is gradually becoming necessary to implement improvements in workplace environments with consideration for elderly workers [4-6]. The first points that are usually emphasized when considering indoor environments are temperature and humidity. Although a well-known health problem associated with rising temperatures is heat stroke, the temperature at which a surge in the number of cases occurs depends on age group. Although a surge in the number of heat stroke cases in people aged 15 to 64 years occurs at $35^{\circ} \mathrm{C}$, in people aged over 65 years it occurs at $33^{\circ} \mathrm{C}$. Moreover, temperatures in excess of $33^{\circ} \mathrm{C}$ induce circulatory system disorders in people older than 65 years, and the death rate associated with heart attacks increases [7-9]. Elderly people have a high risk of heat stroke, not only during the day but also at night, and they also have a reduced sensitivity to heat, so the possibility that countermeasures are taken late increases [10]. In such cases adverse effects cannot be prevented by measures involving voluntary action, including by the provision of air conditioning. Therefore, heat stroke countermeasures by methods that do not depend on the sensory functions of the target person are needed. For this reason, the Association for Preventive Medicine in Japan recommends that temperature and humidity measurements be made at indoor workplaces twice per month. Also various studies have measured the effectiveness of building insulation on daytime temperature rise restraint. However, its influence at night has not been so well studied.

Moreover, global warming is an international concern and various domestic organizations in Japan are making efforts to address this problem $[11,12]$.

Taking into account the above circumstances, we propose a new temperature control method for indoor workplaces using heat-resistant paint. If the temperature of indoor 
workplaces can be adjusted to the most comfortable level, the number of health-related incidents during work can be reduced, and a pleasant work environment can be offered to elderly workers. Specifically, the proposed method prevents rising temperatures by applying energy-efficient materials that reduce the emission of $\mathrm{CO}_{2}$ without the need for air conditioning devices. The method uses a heat-resistant paint developed by Nissin Sangyo Co., Ltd., which has the largest market share among energy-saving paints. This paint contains ceramic beads with insulating properties. We have already published several reports indicating that this heat-resistant paint is superior to other paints [13]. Here we describe the experimental verification of the paint's effectiveness on cargo containers and communal buildings.

\section{Verification Experiment Using Cargo Containers}

\subsection{Experimental Setup}

In the first verification experiment, two containers $(\mathrm{H}$ : $2591 \mathrm{~mm}$, D: $2438 \mathrm{~mm}$, L: $3658 \mathrm{~mm}$; Figure 1) were placed side by side. These containers were made of steel. One container was coated with the paint containing ceramic beads (container A, right in Figure 1(a)), and the other was an uncoated, ordinary cargo container (container B, left in Figure 1(a)). The effectiveness of the proposed temperature control method was verified by comparing temperature fluctuations in both containers during the summer. The evaluation index was based on measurements of internal temperature at five points, as shown in Figure 1(b). In addition, external temperature was measured to evaluate the effect of the method. The experimental conditions are detailed in Table 1.

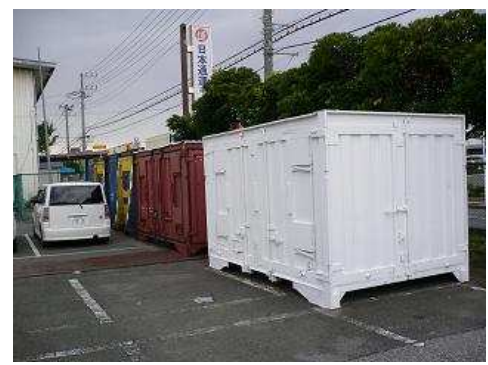

(a) Cargo Containers

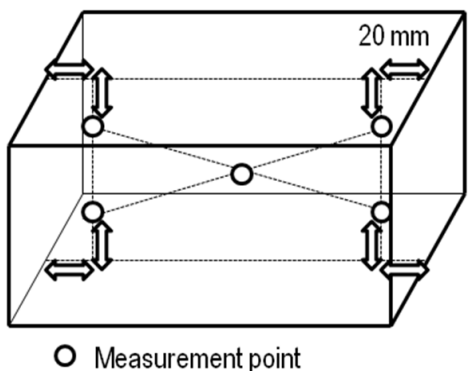

(b) Measurement points of container internal temperature

Figure 1. Experimental setup.
Table 1. Experimental conditions (cargo containers)

\begin{tabular}{ll}
\hline Contents & Details \\
\hline Experimental location & Chiba PRF, east of Japan. Latitude \\
& $35.6^{\circ} \mathrm{N}$ and longitude $140.1^{\circ} \mathrm{E}$ \\
Measurement period & 19 Sept. to 4 Oct., 2006 (2 weeks). \\
Measuring instrument & RSW-20s, Espec. (for temperature) \\
Measurement interval & 30 minutes \\
\hline
\end{tabular}

\subsection{Results and Discussion}

Figure 2 shows temperature fluctuations inside and outside the containers during the measurement period. It is clear from the figure that container $\mathrm{A}$ had a lower internal temperature than container B. There is also visible correlation between outside and internal container temperatures, with temperature fluctuations inside following those outside.

Next, we calculated average temperatures over the measurement period from measured daily peak temperatures inside the container (Figure 3). The average internal temperature in container A was $29.2^{\circ} \mathrm{C}$, compared with $37.0^{\circ} \mathrm{C}$ in container B. This shows that the proposed system was able to lower the temperature by $7.8^{\circ} \mathrm{C}$. Moreover, the largest temperature difference, on 28 September, was $18.5^{\circ} \mathrm{C}$. These results suggest that the proposed method enables temperature control without energy consumption.

Insulation materials were not included in the container used in the experiment. Therefore, we conducted an experiment that included insulation to verify the effectiveness of the proposed method in collective housing, as described in the next section.

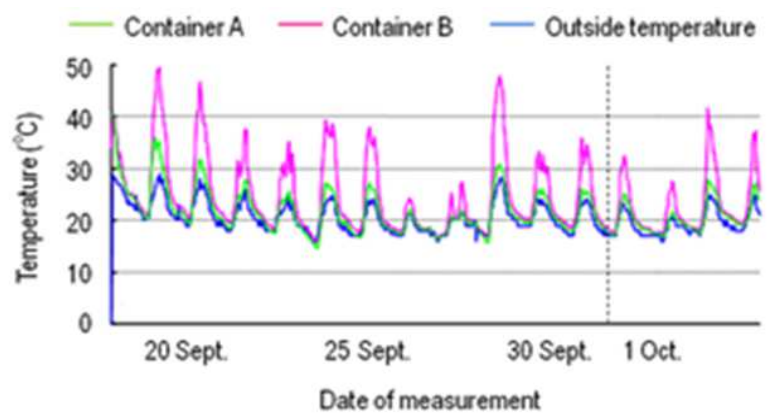

Figure 2. Temperature fluctuations inside and outside containers.

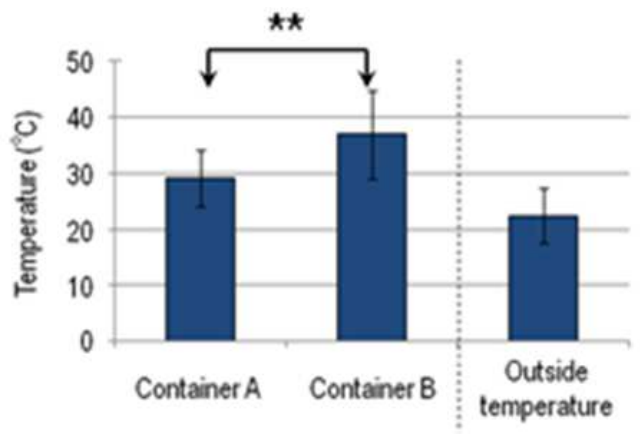

$(* *: \mathrm{p}<0.01)$

Figure 3. Average peak temperature during measurement period. 


\section{Verification Experiment Using a Communal Building}

\subsection{Experimental Setup}

Figure 4(a) is a photograph of the target buildings, which are two adjacent conventional houses of identical construction. The roof and external walls of one building were coated with the paint containing ceramic beads (house A), and the other was left as a normal, uncoated house (house B). The evaluation index was based on measurements internal temperature at 9 points, as shown in Figure 4(b). The external temperature was also measured. The effectiveness of the proposed temperature control method was verified by comparing temperature fluctuations in both houses during the summer. We also compared the amount of electricity consumed by each house's air-conditioning system to maintain a constant indoor temperature. The experimental conditions are listed in Table 2.

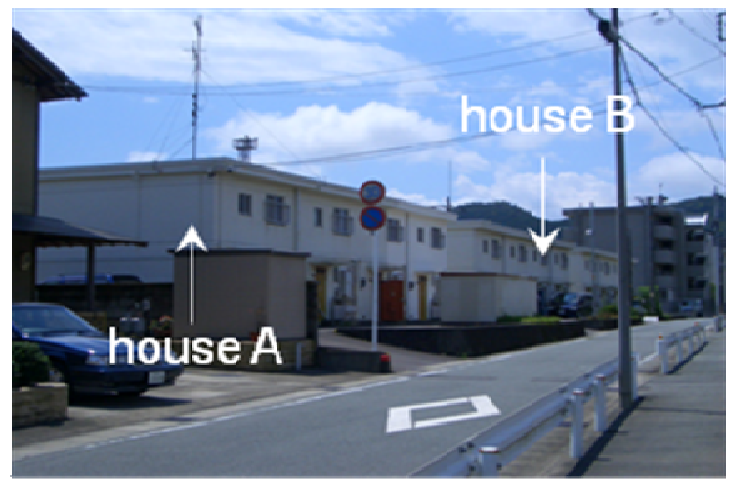

(a) Communal buildings

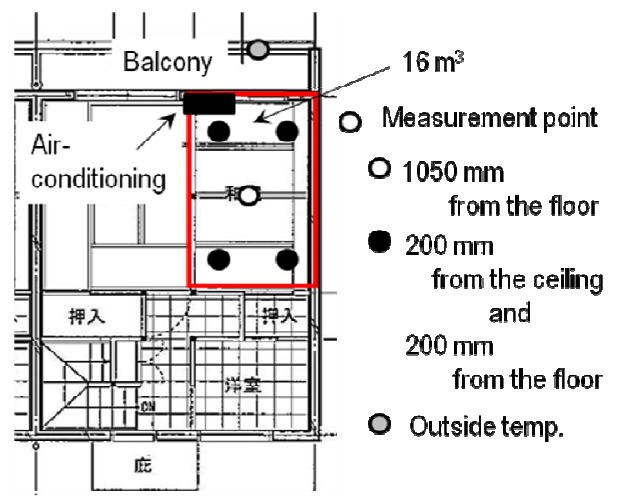

(b) Measurement points of house internal temperature

Figure 4. Experimental setup.

Table 2. Experimental conditions (communal building)

\begin{tabular}{ll}
\hline Contents & Details \\
\hline Experimental location & $\begin{array}{l}\text { Mie PRF, west of Japan Latitude } 34.1^{\circ} \mathrm{N} \\
\text { and longitude } 136.2^{\circ} \mathrm{E}\end{array}$ \\
Measurement period & 25 Aug. to 5 Sept., 2007 (12 days). \\
& RSW-20s, Espec. (for temperature). 3169, \\
& HIOKI. (for power consumption) \\
& 5 minutes. (for temperature). 10 minutes. \\
Measurement interval & (for power consumption) \\
\hline
\end{tabular}

\subsection{Results and Discussion}

Figure 5 shows the temperature fluctuations inside and outside the houses for one week, from 28 August to 3 September. It is clear from the figure that house A had a lower indoor temperature than house B.

Next, we calculated average peak temperatures over the measurement period from the daily measured peak temperatures inside the houses (Figure 6). The average indoor temperature in house A was $27.9^{\circ} \mathrm{C}$, compared with $29.4^{\circ} \mathrm{C}$ in house $\mathrm{B}$, indicating that the proposed system was able to reduce the temperature by $1.5^{\circ} \mathrm{C}$. The difference between results of the house and container experiments can be attributed to insulating materials used in the houses' construction. Thus, the proposed method is effective even in buildings with such materials.

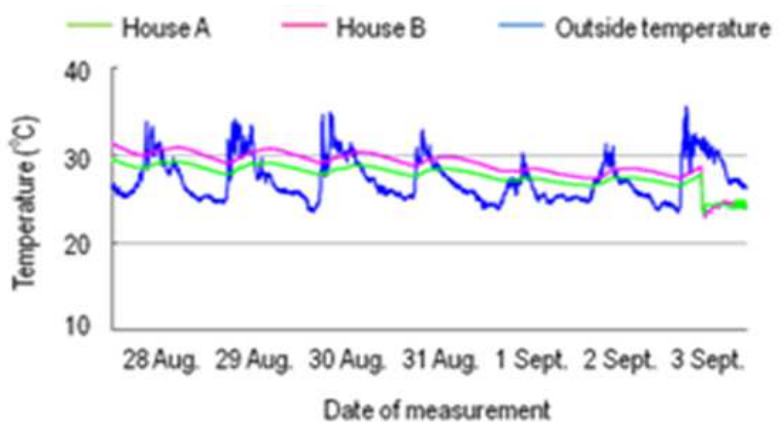

Figure 5. Temperature fluctuations inside and outside houses

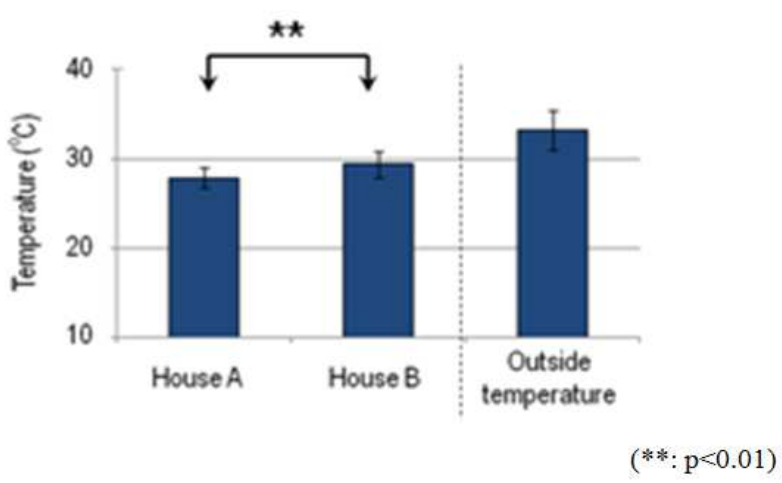

Figure 6. Average peak temperature in measurement period

Figure 7 shows an example of electricity consumption measurements during a period of air-conditioning use. It is evident from the figure that electricity consumption in house A was lower than in house B. In addition, because the air-conditioning system's thermostat was set to $26.0^{\circ} \mathrm{C}$ in the experiment, the air-conditioning system switched off when the indoor temperature fell below that value. In the figure, this state is indicated by an electricity value of zero.

Table 3 shows electricity consumption on each measurement day (from 25 to 27 August and 4 to 5 September). On average, the consumption in house A was $3.7 \mathrm{kWh} /$ day, compared with $4.6 \mathrm{kWh}$ /day in house B, showing that the proposed system was able to reduce consumption by $20 \%$. 


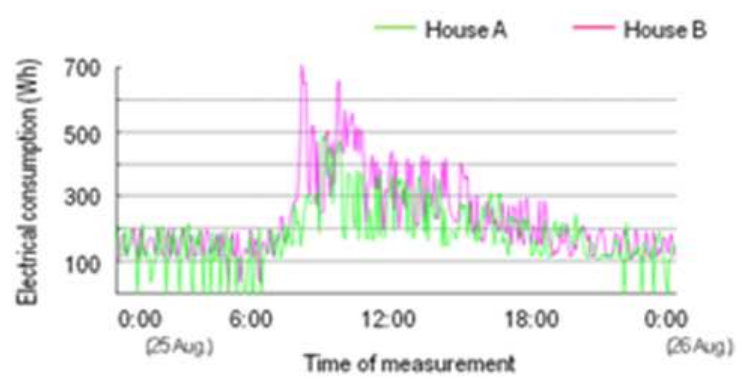

Figure 7. Example of electricity consumption measurements during times of air-conditioning use.

Table 3. Electricity consumption on each day of measurement $(k W h)$.

\begin{tabular}{cccc}
\hline Date & House A & House B & Ratio (A/B) \\
\hline 25 Aug. & 2.73 & 3.45 & 0.79 \\
26 Aug. & 4.98 & 6.62 & 0.75 \\
27 Aug. & 3.85 & 4.85 & 0.79 \\
4 Sept. & 3.77 & 4.56 & 0.83 \\
5 Sept. & 3.14 & 3.48 & 0.90 \\
Average & 3.694 & 4.592 & 0.804 \\
\hline
\end{tabular}

\section{Effect at nighttime}

We compared the internal temperatures during the daytime and nighttime, for both containers and buildings. In the containers, the daytime effect is remarkable, and there is no difference at night. However, in the buildings, there is difference of temperature in both the daytime and nighttime. Therefore, we compared the air conditioning energy saving rates for daytime and nighttime. We set division between daytime and nighttime by the period of daylight.

Table 4 and Figure 8 show the electricity consumption results. The energy saving rate for air conditioning during daytime was $26.3 \%$, and during nighttime it was $15.3 \%$. Thus, this heat-resistant paint can improve indoor temperatures in a building not only during the day, but also at night. This suggests that using heat-resistant paint can produce an environment in which the possibility of heat stroke for elderly people at night is reduced.

Table 4. Electricity consumption on measurement (W)

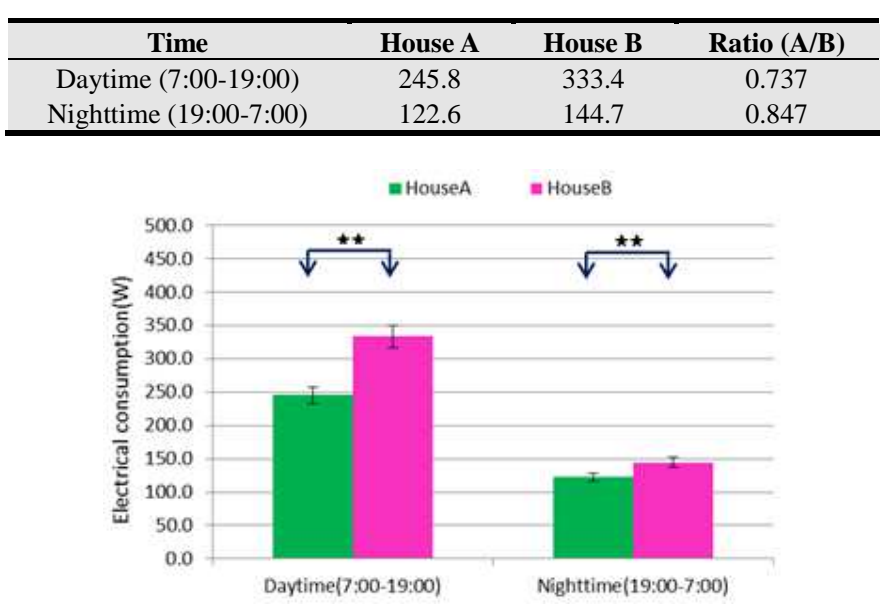

(**: $\mathrm{p}<0.01)$

Figure 8. Consumption electricity comparison for daytime and nighttime.

\section{Conclusions}

In this study, two verification experiments were conducted to test a proposed temperature control method in cargo containers and conventional houses. The results can be summarized as follows.

- In an environment with an average ambient temperature of $24.6^{\circ} \mathrm{C}$, the peak temperature inside a cargo container with the proposed system was $7.8^{\circ} \mathrm{C}$ cooler than in an ordinary container.

- In an environment with an ambient temperature greater than $33.1^{\circ} \mathrm{C}$, for any arbitrary setting of room temperature inside an ordinary house, the proposed system can reduce energy consumption by $20 \%$ compared with an air conditioner alone.

- The energy saving rate for air conditioning in a building was $26.3 \%$ in the daytime, and for the nighttime it was $15.3 \%$.

\section{Acknowledgements}

The authors express great thanks to Nissin Sangyo Co., Ltd. for their financial support and technical assistance.

\section{References}

[1] Ilmarinen. J, Tuomi. K, Eskelinen. L, Nygard. C-H, Huuhtanen. P \& Klockars., Background and objectives of the finish research project on aging workers in municipal occupations, Second. J. Work Environ. Health, Vol.17, Supplement 1, 1981, pp.7-11.

[2] Kawakami. M \& Kajihara. Y (2001), A model for activating the elderly in the production system, Proc. of NES2001, 2001, pp.359-363.

[3] Seisamo. J \& Ilmarinen. J (1997), Life-Style aging and work ability among active finish workers in 1981-1992, Second. J. Work Environ. Health, Vol.23, Supplement 1, 1997, pp.20-26.

[4] Nygard. C-H, Huuhtanen. P, Tuomi. K \& Martikainen. R, Perceived work changes between 1981 and 1992 among aging workers in Finland, Second. J. Work Environ. Health, Vol.23, Supplement 1, 1997, pp.12-19.

[5] Haermae. M \& Ilmarinen. J, Towards the 24-hour Society-New Approaches for Aging Shift Workers?, Second. J. Work Environ. Health, Vol.25, No.6, 1999, pp.610-615.

[6] Huuhtanen. P, The aging worker in a changing work environment, Second. J. Work Environ. Health, Vol.14, Supplement 1, 1998, pp.21-23.

[7] Ilmarinen. J, Aging workers, Occupational \& Environmental Medicine, Vol.58, Issue 8, 2001, pp.546-552.

[8] Kondo. M, Working-hours management for prevention of heat disorders in workplaces at high temperature, Journal of working environment, Vol.29, No.4, 2008, pp. 62-70.

[9] Shishime. T, Promoting countermeasures on urban heat island towards low carbon society, Environmental \& sanitary engineering research, Vol.22, No.3, 2008, pp. 195-198. 
[10] Ministry of Health, Labour and Welfare "Heat stroke prevention leaflet" http://www.mhlw.go.jp/stf/houdou/2r9852000002btf0-att/2r985 2000002btgh.pdf(27/9/2014)

[11] FY 2008 Annual Energy Report (outline) (2009, Aug). Agency for Natural Resources and Energy (ANRE) [Online]. Available: http://www.enecho.meti.go.jp/english/report/outline.pdf.

[12] Global Environment Global Environment News Headline. The
FY 2008 Annual Report on Ozone Layer Monitoring (2009, Sep 14). Ministry of the Environment Government [Online]. Available: http://www.env.go.jp/en/headline/headline.php.

[13] Takashi Oda, Masato Tazawa, Takeshi Kunishima and Kimihiro Yamanaka, Effect of Penetration Depth of Far-infrared Radiation into Architectural Wall, Proc. of Grand Renewable Energy 2014 International Conference and Exhibition, (accepted). 